\title{
Categories of difference in science and policy - reflections on academic practices, conceptualizations and knowledge production
}

\author{
Martin Bak Jørgensen
}

\begin{abstract}
Categories of difference have a crucial position in academic research as well as policymaking. They serve to distinguish and differentiate between groups in society. They can appear in the shape of crude dichotomies or in complex and sophisticated forms resting on constructivist and intersectionalist perspectives. Nevertheless, using categories of difference also creates something into existence and there may be implications through the particular application of specific categories. This article reflects on how categories of difference are constructed and employed in research, legislation and policy discourse. By looking at different approaches used by qualitative and quantitative researchers, as well as at how specific concepts enter policy-making and legislation, I want to address a number of questions about how we as researchers understand and work with categories of differences. The article will mainly consist of a theoretical discussion, but will use two main empirical examples of race and religion. The article aims to provide tentative answers about what the consequences of particular uses of categories and concepts could be.
\end{abstract}

Keywords: categories of difference; methodological challenges in qualitative and quantitative studies; enumeration; reflexive sociology; policy-making; race studies; studies of religion

Please cite this article as: Jørgensen, M. B. (2012). Categories of difference in science and policy reflections on academic practices, conceptualizations and knowledge production. Qualitative Studies, 3(2): 78-96.

\section{Introduction ${ }^{1}$}

This article reflects on how categories of difference are constructed and employed in research, legislation and policy discourse. By looking at different approaches used by qualitative and quantitative researchers, as well as at how specific concepts enter policy-making and legislation, I want to address a number of questions on how researchers understand and work with categories of differences. My aim in this article is to put forward questions that could serve as a basis for reflection, rather than to provide definitive answers for my own questions. As researchers within the field of research on minorities broadly, and on categories of difference, we are all engaged in such analytical practices. Hence, I want to provide an analysis of how different fields of academia employ categories of difference and identify the dominating discourses in the particular fields. The article will mainly consist of a theoretical discussion, but will use two main empirical examples of race and religion. The examples will contextualize the theoretical discussions. The first one will focus on the dispute of 'race' as a category for enumeration and as an analytical concept. The second one will look into how the category of religion is used in academia. Both sections will relate to the theoretical discussion of the article. The article aims to provide tentative answers about what

\footnotetext{
${ }^{1}$ I would like to thank the editorial team of this special issue for a very dedicated and productive editorial process. I am also grateful for the helpful and constructive comments and suggestions from the peer-reviewers.
} 
the consequences of the use of categories and concepts could be. While we can easily point to both historical and contemporary pitfalls we can also point to several studies taking a highly productive and constructive perspective. This article will point to some of the methodological challenges to be met in this field and following from this discussion will point to some of the answers offered by studies which potentially could present a forward-looking perspective. The material analyzed consists of academic texts, ongoing research projects, policy documents from academic associations, calls for papers for conferences, legislative and policy documents, statistics, interviews, and academic websites for popular dissemination of research.

\section{Researching categories of difference}

Policy discourses revolve around central distinctions between deserving and undeserving groups, for instance on who has access to a country and who has not, who is entitled to rights and services, and so on (Yuval-Davis, 2006a). Such distinctions may be based on categories of race, ethnicity, gender or social divisions. What is common for these is that they are categories of difference which serve to position the particular individual or group in a social and economic location. Similarly, what is common for most of the different academic approaches - despite disciplinary demarcations and intentions of wanting to analyze discrimination, marginalization or inequalities, for instance is that in order to study immigrants and ethnic minority communities, the focus necessarily ends up being on differences. In order to enter this research field, studies inevitably reproduce various distinctions between ' $u s^{\prime}$ and 'them'. Academic approaches 'write differences', so to speak, into the texts they produce (Nayak, 2006; Rosenblum and Travis, 2008). Research may itself construct categories of difference, for instance by racializing research (Ali, 2006). From a normative position, research should arguably have as one of its aims to be responsible for knowledge production, which is made available and relevant for policy-makers. This, in theory, would help to inform and improve policy-making. However, political and academic discourses overlap to some degree, and many academic studies reproduce the very categories of difference that they may be seeking to challenge within policy. We might, therefore ask questions such as: does government funding for research have an effect on academic conceptualizations and terminology relating to difference (see Jørgensen, forthcoming)? Is this a problem, and if so, how do we then write about difference at all? Conversely, we can also find research which seeks to deliberately spur social change and deconstruct popular myths. Categorization is not only an 'evil'. It is also a means of identifying problems and social issues and put them back on the agenda. Moreover from a theoretical scientific perspective one can claim that all (social) research builds on categories and there is no way to escape the use of such. The task is, therefore, to make sure that reflexivity - following Bourdieu's objective of reflexive sociology - is integrated into theory, design and analysis.

\section{Categories that matter?}

1. those that belong to the Emperor,

2. embalmed ones,

3. those that are trained,

4. suckling pigs,

5. mermaids,

6. fabulous ones,

7. stray dogs,

8. those included in the present classification,

9. those that tremble as if they were mad, 
10. innumerable ones,

11. those drawn with a very fine camelhair brush,

12. others,

13. those that have just broken a flower vase,

14. those that from a long way off look like flies (Borges, [1942]).

This list is taken from a 1942 work by Borges. Borges claims that this list appears in an ancient Chinese encyclopedia entitled Celestial Emporium of Benevolent Knowledge, where it was discovered by a translator and later found by Borges himself. The taxonomy will seem absurd and in no way comprehensive for any system of classification for most people. Borges' point was precisely to illustrate the arbitrariness and irrationality of cultural systems of categorization and classification. However, this taxonomy also triggers reflection. Are these categories really less applicable than the classification systems that we meet, for instance, in policy-making or in the social sciences? We see repeatedly how specific categories are used to divide, distinguish and enumerate different individuals and groups, and some of these create, if not unintelligible, then arbitrary positions. One striking example taken from Danish legislation was the adoption of the so-called 'Tunisian law' (Tuneserloven) from 2008. ${ }^{2}$ This particular law was adopted to restrict the movements of a 36-yearold Tunisian man living Denmark at the Sandholmlejren detention centre close to Copenhagen as he was perceived to be a threat to the illustrator of one of the Muhammad cartoon pictures, Kurt Westergaard. ${ }^{3}$ As Westergaard felt threatened and a political majority felt it necessary and just to make sure that this category of persons did not move around, a new law proposal was made and later adopted. ${ }^{4}$ The category of 'the Tunisian' in Danish society was thus legally brought into existence, to ensure that one person behaved in a specific way. To sum up, society makes use of classifications that may be more or less incomprehensible to most of us. Categories are social constructs which define who and what is included and excluded. They can serve as means for securing privileges and dominance of the powerful over the less powerful. At the same time they can reveal inequalities and social problems and produce empirical knowledge on social divisions and help to deconstruct established hierarchies by de-naturalizing what we take for granted. YuvalDavis writes about categories, such as gender, race, class, and nationality, and argues that 'these are not just different categories of social location, but categories that also have a certain positionality along an axis of power, higher or lower than other such categories' (Yuval-Davis, 2006a: 199).

\footnotetext{
${ }^{2}$ The law is an amendment of the Aliens Act, which restricts the movement of people on so-called tolerated stay (tålt ophold), by imposing daily reporting duties. By breaching this declaration a person can be sentenced to up to one year imprisonment. People positioned in this category are not wanted in the country, but cannot leave either because of threats to their security in the country of origin.

${ }^{3}$ In 2005 the daily newspaper Jyllands-Posten asked a number of cartoonists to draw the prophet Muhammad. Jyllands-Posten declared that this publication was an attempt to contribute to the debate regarding self-censorship and criticism of Islam. The cartoons led to a controversy and global protest.

${ }^{4}$ The Tunisian man was allegedly seen close to the home of Westergaard, who had previously been attacked in his home. As Westergaard lived in different region of the country from where the detention centre was located, legislators could find no reason why the Tunisian man should be at that place (near Westergaard's home) at that time, which legitimated the legal action.
} 
Categories of difference hence establish specific positions which are defined by specific attributes. Foucault has described these as subject positions (Foucault, 1969): subjects are offered a position by the people, systems (and discourses) they interact with. Some positions are recognized and accepted and others are resisted or redefined (Davies and Harré, 1990; Jensen, this issue). An individual does not only belong to one identity category, however. People are simultaneously embedded in different categories. As Yuval-Davis argues, it is important to acknowledge that "while all social divisions share some features and are constructed by/intermeshed with each other", they are not reducible to each other (Yuval-Davis, 2006b: 200; see also Walby, 2007; also Jensen, this issue). Not all categories of identification may be important at the same time. Selfidentifying as religious when crossing the doorstep of the church may carry more importance than one's class position at that particular time and place. Institutionally embedded categories of ethnicity and citizenship status will be difficult to transgress, whereas other categories will be possible to resist. Furthermore, the question of which categories matter becomes crucial when turning the perspective to the research practices. When students and scholars single out a specific category as important and employ that category for understanding and analyzing social relations and identities then they - and all of us engaged in this field - also write specific differences into the story. The construction of collective groups from such categorizations and identity markers may be both crude and misguiding. Labeling, categorizing or, in short, discursive practices also have social and material consequences, however, as they relate to practice.

Categories and positioning in this sense are connected to practice. Categories are not only formal classifications that can be ascribed (socially and politically through discourse, or legally, as in the Tunisian Law discussed above), but they are something that people do or practice. This relation between discursive and social practice has long been a focus for the social constructivist approaches within social science and humanities (e.g. Berger and Luckmann's seminal book from 1966). The social constructivist ${ }^{5}$ position is prominent among the researchers of ethnic and racial relations (see contributions in Ferrante and Brown, 1998). Many articles will begin with a disclaimer, saying that such categories have no objective existence e.g.: "[T] here is no such thing as race" writes Nayak, for example (Nayak, 2006: 411; italics in original). Constructivist approaches hence regard differences as socially constructed and arbitrary. They look into the classification system itself and ask how it was made and by whom. Who are the categorizers?

Writing and talking about differences also creates difference. That categories of difference do not have an objective basis (for the constructivist position) does not imply that this recognition has lessened the impact of for instance "racialization as mode for the social organization and regulations of human society through capital and labour" as Nayak writes after his initial positioning (ibid: 411-412; also kennedy-macfoy and Pristed Nielsen, this issue). The essentialist perspective, in contrast, regards categories of difference as 'essential' in fundamental ways, for example, on the basis of race, gender, or sexuality. Here, differences have an objective material basis. This perspective takes into consideration what causes people to be different, rather than how such differences are constructed (see Jenkins, 1996 for a discussion). This would be a conventional point of departure for statisticians. Differences are viewed as natural, and what can be analyzed is how categories of difference become a basis for repression and segregation. Within policy-making,

${ }^{5}$ I do not distinguish between constructivism and constructionism here. 
categories are viewed as an essential element, which determine how entitlements or redistributions are organised. Categories are the basis for understanding Laswell's famous dictum when he describes politics as "who gets what, when and how" (Laswell, 1936). We meet categories in political life and policy-making where they construct "hierarchies of civic stratification" to use Morris' terms (Morris, 2002). Policies are designed to have an impact - positive or negative - on specific groups. Sometimes the target group may be the population as a whole, but at other times, the target group may be narrowly defined, as the case with the Tunisian man illustrates.

Researchers also work with categories of difference. It is difficult to imagine a scenario where researchers did not work with categories of difference, however, this is particularly so within the research fields of minorities, international migration and ethnic relations, including studies on religion. Here, the point of departure will often be on differences between one group (national, ethnic, or ethno-cultural, for instance) and another. Some of these differences may hold derogative connotations and/or sediment differences between 'us' and 'them' and others may help to identify inequalities and systems of exclusion or deconstruct popular myth about particular target groups. Is it really possible to get beyond the use of such concepts? The answer would be no, but neither would it necessarily be beneficial. Categorization is a crucial element of social sciences. Categorization can have both repressive and empowering effects but it is first and foremost a methodological and theoretical challenge rather than a matter of trying to get beyond categories. The solution is not to do away with categories but showing awareness of the epistemological assumptions implied in analysis. If, for instance, we view racial or ethnic differences from a perspective of cultural politics of differences, as Hier and Walby do, race and ethnicity will be analysed as real and determinant of the power dynamics of the dominant society (Hier and Walby, 2006:84). However, a perspective linked to a social politics of redistribution grants explanatory importance to differential access to resources on a collective level: race and ethnicity are analysed as subordinated to other categories. For Hier and Walby the aim is to carve out an approach that is "capable of negotiating the intricacies of multiple processes of individual and group formation and social incorporation in a way that refrains from essentializing ethnicity/race or from reducing race/ethnicity to another level of effectivity" (ibid: 102; for a similar argument see Fraser, 2003).

This section has outlined how categorization can be understood within different paradigms - the social constructivist and essentialist - and how it is linked to practice. Deconstructing the ontological basis of categorization does not solve the problem of categorizing, however. In the following sections, I will look more closely at the use of categories and knowledge production within scientific fields and the links to policy-making and knowledge production, and discuss different rationales identified for working with categories of difference.

\section{For the sake of...? Statistics - 'Science without scientists'}

Bourdieu used the notion of 'science without scientists' specifically about statistical research approaches (Bourdieu, 1990). His basic claim was that this type of research has stopped being reflexive due to exaggerating the 'systematicity' of the studied phenomena. According to Bourdieu they - the researchers - have stopped reflecting on how researchers themselves import biases into the studies. This is not a repetition of the somewhat trivial critique of quantitative studies coming from qualitative studies. Bourdieu's argument was not that quantitative studies are positivistic and therefore 'bad'. Rather, he suggests that all researchers should engage in a reflection on the biases and prejudices they carry with them, and consider how to challenge these. Disregarding the last 
disclaimer we obviously can discuss if Bourdieu was correct in his diagnosis. The risk here is to draw up a caricature or a 'straw man' which is easy to refute but which might not bring the discussion forward and even worse - risk overlooking what statistics can do. As Best has argued we need statistics - good statistics - to be able to talk sensibly about social problems (Best, 2004). The solution, then, is not to give up on statistics, but to meet the statistics which we encounter and produce reflexively and critically.

Statistics can be defined as conventions representing legitimate (and normative) divisions of the social world. They are used for designing policies, for representing societies and for building 'objectivation' of social processes (cf. Bourdieu; Rallu, Piché and Simon, 2006). Working with statistics demands that we ask extremely fundamental questions such as: should we count, why should we count, and how should we count? (Callister et al., 2009) Within the field of migration and ethnic relations, the answer to these questions differs immensely. In Denmark, the political perception of the increasing complexity of the 'immigration issue' also creates the need for more subtle definitions in order to direct policy or legislation towards specific groups. Thus, in 1991, (inspired by Norway), Statistics Denmark introduced a distinction between 'immigrants' and 'descendants of immigrants'. The reasoning was that it was necessary to have more refined categories in order to ascertain how many people with a foreign background are incorporated in Danish society (Jørgensen, 2009). In contrast, 'descendants of immigrants' are included in the official statistics of the Statistiska Centralbyrån in Sweden. It can be argued that the distinction between 'immigrants' and 'descendants of immigrants' essentializes the 'Otherness' of immigrants, as well as of their descendants. As people born in Denmark, the latter groups are kept in a status of being 'not quite Danes'. Statistics Denmark also distinguishes between immigrants from Western and non-Western countries. This can be considered a very crude dichotomy. Despite having different nationalities, we could expect immigrants from for instance Japan, Russia and Ghana to differentiate on many other socio-economic characteristics all ignored in the dichotomy of Western and non-Western countries. In Germany, until recently, there was a strong reluctance to count ethnic minorities due to the historical trajectory and experiences with Nazism. Statistics contained no information on descendants, but the reconfiguration of the Mikrozensus has made it possible, since 2005, to also trace the descendants of immigrants, and consequently made longitudinal analyses possible. This possibility has been perceived very positively compared to the situation in Denmark, where the category has been criticized for marking people with an ethnic background other than Danish as deviant. In the German context, it has revealed marginalized people who are not part of the statistics. ${ }^{6}$ A last example from Southern Europe is Portugal, which does no counting whatsoever, with the result that there are no policies for protection against discrimination, as there is no data on the scope of discrimination. The approach is that not counting makes the problem disappear. That was also the case in Brazil, to take an example outside Europe, where the category of race was abandoned, with the result that racism is no longer recognized, despite obvious divisions between racialised groups within Brazilian society. ${ }^{7}$ Subsequently, it would be too

\footnotetext{
${ }^{6}$ Interview with Ulrich Raiser, Der Beauftragte des Berliner Senats für Integration und Migration, Berlin, December 2006.

7 As also discussed in a recent article 'Affirming a divide' in the Economist January 2012. http://www.economist.com/node/21543494
} 
simplistic to conclude that statistics are either good or bad because they can have (intentional and unintentional) positive or negative effects.

The proliferation of data - is it better?

The demand for data has increased as migration and integration policies have become institutionalized throughout Europe (in particular). Policy-makers and governmental bodies at the European level have asked for comparative quantitative data for monitoring and evaluation of the effects of policies. The adoption of the 'Regulation on Community Statistics on Migration and International Protection's by the EU Member States was a leap forward in harmonizing data collection of immigration and asylum statistics. Today, there are several datasets available at the national and European levels. The COMPSTAT and PROMINSTAT projects have mapped these datasets, and assessed their comparability. However, the request for harmonized data is not without dangers. When breaking down the possible classification of population groups according to characteristics that refer to migration or foreign background, Kraler and Reichel in the final report issued by the PROMINSTAT project found that this provided no less than 18 distinct categories (PROMINSTAT, 2010: 37). This will make it possible not to 'lump' people together in a few crude aggregated groups, but it also provides an overload of categories for the researcher to work with. Generally, the data increasingly include additional information on migration-related information beyond citizenship and country of birth. Data allowing for more detailed breakdowns are becoming available. This is a consequence of the EU regulation and work by statistical agencies like Eurostat to standardize national systems for data collection. Similar exercises have been undertaken in relation to statistics on discrimination at the EU level and in relation to gender issues. Data on gender is also becoming desegregated according to various social, legal and identity categories for women (see Yuval-Davis, 2006b). However, introducing more categories also brings out more complexities. Adding, for instance, membership to a religion or a religious community may be very ambiguous. Many people would associate with more than one religion, at the same time (for example in Japan). Expressing data on religious affiliation could be dangerous for some people, where specific religious traditions are suppressed by the state, for example Christians and the Falun Gong movement in China. The same could happen with regards to ethnicity. Anderson's historical analysis has shown the often devastating effects that the introduction of mutually exclusive census categories has had on colonial societies in which peaceful coexistence depended on categorical fluidity (cited in Yuval-Davis, 2006b: 205; see also Anderson, 1991). Opening up the Pandora's box of more categories may have further implications. Groups and persons not necessarily interested in being recognized or identified as part of a social group may be compelled to do so.

The consequences of counting?

We still need to reflect on how categories are constructed and what the implications of the individual categories are. When the category of non-Western immigrants is applied by policymakers and researchers alike, what are the consequences? Or what is the implication of the category of 'bilingual students' (Aidt and Hervik, 2009)? Rallu, Piché and Simon (2006) point to four different uses of counting and not-counting. Firstly: counting for dominance and exclusion - this mode of enumeration was used in particular countries (such as Britain, Netherlands, Portugal, inter

\footnotetext{
${ }^{8}$ Regulation (EC) No 862/2007.
} 
alia) with a colonial past and the Apartheid system in South Africa. The second type is deliberately not counting in order to promote national integration and assimilation (as in France) so that newcomers become like the majority population and not stand out statistics; counting would emphasize differences instead of commonalities, and unification requires invisibility. Thirdly, counting in the name of multiculturalism and national hybridity - differences should be visible. Lastly, counting should be done for the purposes of anti-discrimination, serving a policy monitoring function. It is important to be explicit about why counting is necessary. It can be a tool for identifying and combating discrimination and racism, but conversely it could be used, and has been used, to divide the nation, to stigmatize and it can lead to prejudice and discrimination (Callister et al., 2009).

Another problem pertaining to the use of statistics is the mismatch between different disciplinary understandings of the categories such as ethnic, national, or cultural, and people's self-chosen identities. Overemphasizing one category of difference (and identification marker), e.g. studying 'Muslims', is only one side of the coin, however; we also find situations where claims for a specific identity are rejected as St Louis has shown in his research (2005). Hence, the challenge lies not only in reflexivity and sensitivity when applying categories of difference analytically, but also in understanding the dynamics of contention found in identity politics. In various disciplines working on the field of migration and ethnic relations (anthropology, ethnography, sociology, political science, human geography, and cultural studies), the social constructivist paradigm has become dominant in explaining and understanding various forms of categorization. At the same time, processes of globalization and transnationalism have created new types of belonging and selfidentification based on hybridity and mobility, and new types may constantly be emerging. We accept these new categories in our research. We study them and make analyses of transnational and cosmopolitan identities, but when we turn to statistics, problems arise. Can statistical categories at all capture multi-dimensional identities, and should they? They do present a methodological challenge pertaining to distinctions between subjective identifications and objective categorizations. Mobility brings forth a problem of reliability as the same person risk turning out up several places or only stay within a specific territory for a limited time; self-identifying with multiple identities does the same (Simon, 2011). There are many difficulties, but the solution is not to turn to methodological nationalism (Wimmer and Glick-Schiller, 2002) and once again focus on the nationstate as the only 'container' organizing the social world and social divisions. I would suggest that there are still more benefits to counting than not, drawing on the arguments above, but the research communities need to develop and refine the categories used for the particular types of counting.

In the next two sections I will contextualize the previous theoretical discussion in two different cases as also described in the introduction. The first section will focus on the dispute about race and look into how race has been applied as a category for enumeration and as an analytical concept within academia. The subsequent section discusses how the category of religion (and especially Islam) has reignited the problems embedded in the concept of race - or at least call for similar types of reflections and analytical sensitivity.

\section{The dispute about race}

The question of race has been central in the consideration of the Office of Management and Budget (OMB) in the US when seeking to improve the collection of data in the second part of the 20th century. In the end, OMB issued the Statistical Directive No. 15 'Race and Ethnic Standards for 
Federal Statistics and Administrative Reporting', which defined four racial categories and one ethnic category: American Indian or Alaskan Native, Asian or Pacific Islander, Negro or Black, White, and Hispanic (US Census Bureau, 1977; see also Rosenblum and Travis, 2008: Section 1). Diversity has increased in US society since the 1970s, and in the 2000 census a person could list him/herself as being member of more than one racial group. Still, there were obvious problems: people from Middle Eastern countries still had to register in the racial category 'white', as there was no ethnic category for Arabs or Middle Eastern people. The directive from 1977 was changed in 1997 after a long series of hearings, which also included critique from research communities but discussions have continued. ${ }^{9}$

The contentions over the category of race reveal different positions between different fields of science. The American Anthropological Association's (AAA) response to the OMB Directive 15 was: "[The AAA] recommends the elimination of 'race' from OMB Directive 15 during the planning for the 2010 Census. During the past 50 years, 'race' has been scientifically proven to not be a real natural phenomenon. [...] social categories such as 'ethnicity' or 'ethnic group' are more salient for scientific purposes" (American Anthropological Association, 1977). In 1998 the AAA issued a new statement, which describes the current policy: "Racial beliefs constitute myths about the diversity in the human species and about the abilities and behavior of people homogenized into 'racial' categories" (American Anthropological Association, 1998). The Association takes over the antifoundational constructivist position on race, and is in line with scholars like Yuval-Davis, and, furthermore, recaptures Thomas' theorem with the statement that: "how people have been accepted and treated within the context of a given society or culture has a direct impact on how they perform in that society" (ibid.). Rightly so, but does avoiding using race as a social category, as an analytical concept or as a category for collecting data change that phenomenon?

The American Sociological Association (ASA) holds the opposite opinion. Data on race should be collected. In a statement on colleting data and doing social scientific research on race from 2002, it is stated that: "the failure to gather data on this socially significant category would preserve the status quo, and hamper progress toward understanding and addressing inequalities in primary social institutions" (American Sociological Association, 2003). The ASA refutes the argument that racial categories embedded with a negative history should not be studied, and argues that race as a social phenomenon "shapes social ranking, access to resources, and life experiences" and, therefore, should be studied, and data based on categories of race should be collected (ibid.). This is in line with the fourth reason for counting outlined by Rallu, Piché and Simon above (counting done for the purposes of anti-discrimination). Academic discussions on race have been less heated and less dominant in Europe; race as a category has not gained the same academic prominence as in the US. Race has a particular position in US history and contemporary society that is not similar to the history of the European countries, which do have widely varying historical colonial legacies (for a discussion of colonial histories in the Nordic region, see Gilroy, 1992; Keskinnen et al, 2009; Said, 1978; 1993). Race has been very visible in political claims-making and identity politics in the US, whereas ethnicity has played a larger role in European countries, where these contestations have also emerged later than in the US (Lentin, 2008). Speaking from a European (or indeed Norwegian)

\footnotetext{
${ }^{9}$ See http://www.whitehouse.gov/omb/fedreg notice 15 and http://www.whitehouse.gov/omb/fedreg directive 15 for a summary of the criticism.
} 
perspective Marianne Gullestad argues that anthropologists primarily have referred to ethnicity rather than race but that in doing so race unobtrusively slips in through the backdoor - and the same can be said for social class and gender (2002; here referred to by Eide, 2010). The UK is a European exception, however, where race still 'matters' politically and as a research field (Squires, 2007: 161). The IRR - Institute for Race Relations - has been in existence for many years, and is responsible for the ranked journal 'Race \& Class'. The highly ranked journal 'Ethnic and Racial Studies' is also published in the UK. Even in the UK, however, research on race is rare. This brief overview of the debate on race shows that there might be reasons for using race as a category for collecting data and explaining social relations.

Rosenblum and Travis write that we should be careful not to assume that what is counted is real: "While census data contribute to the essentialist view that the world is populated by distinct, scientifically defined categories of people [...] not even those who collect the data make that assumption" (Rosenblum and Travis, 2008: 11-12). The OMB for instance puts this very clearly: "The racial and ethnic categories set forth in the standards should not be interpreted as being primarily biological or genetic in reference. Race and ethnicity may be thought of in terms of social and cultural characteristics as well as ancestry" (OMB, 1997: 2). Still, one need not read many lines by scholars like Huntington or Lewis to learn that the world is divided between different cultures with distinct cultural and religious characteristics. This line of thought can be traced back to German romanticism, (for example in Herder's work), and is not a new invention. Yet it is being reproduced, and researchers contribute with essentialist analyses of difference alongside the constructivist outputs also described. Can we get beyond either perspective? Or is this depiction offered here based on too crude positions coming closer to stereotypes than ideal-types? Should we stop writing about race? Gilroy has long called for the reformulation of race and offered a new political language for getting beyond race and racism (for instance Gilroy, 1992; 2000). In a similar manner Nayak advocates critical dialogues between the different positions, and offers a post-race framework (Nayak, 2006). Lieberman argued, from the perspective of physical anthropology and human genetics, that a no-race theory is accepted (1968). Different perspectives dismiss race, but the question is, if this is indeed the way forward. If race is felt by persons identified by this category, voluntarily or involuntarily, should we then not study it? And as critical whiteness studies show the question may be equally pertinent for persons who do not 'feel' race (kennedy-macfoy and Pristed Nielsen this issue; see also Nayak, 2007). Can we only do so by using numerous apostrophes '....' around all our central analytical concepts? Researchers working on ethnicity will experience similar problems. Categories of social division in general carry the danger of being 'naturalized', of being taken for granted. Yuval-Davis argues that: "What is common to all these discourses of naturalization is they tend to homogenize social categories and to treat all who belong to a particular social category as sharing equally the particular natural attributes (positive or negative) specific to it" (Yuval-Davis, 2006b: 199).

In the next section, I will argue that the category of religion in many ways, and particularly so in Europe, has replaced the previous focus on race, and likewise, is intermeshed with categories of ethnicity, and provides an example of how religiosity becomes naturalized in the study of immigrant groups.

\section{From race to religion- same same or different?}


Islam has once again entered the political agenda, spurred by events like the $9 / 11$ terrorist attack in the US, the London bombings of 2005, the 2004 murder of Theo van Gogh in the Netherlands, the 'Arab spring'; by political issues such as different national discussions on integration, riots in the French banlieues in 2005, transnational marriages, but also recently in nomenclature like 'EuroMuslims'. Race seems to have fallen out of the headlines. The riots that took place in August 2011 in London did highlight the category of race as a possible explanation, but most commentators dismissed racial and ethnic explanations (see for instance Guardian, 2011; see the discussion by Murji and Neal, 2011). However, racialization is, nevertheless, dominant in the (crude) modes of explanation as illustrated by British historian Starkly's explanation for the 2011 summer riots in England (see BBC, 2011). Neither is race prominent in calls for papers, workshops, conferences, special issues in European contexts. Researchers have argued that islamophobia has replaced racism (although these categories very likely intersect with each other). Perhaps illustrating the focus on religion, the center for Race and Gender at Berkeley, University of California has recently initiated 'The Islamophobia Research and Documentation Project' (IRDP) and launched the new Islamophobia Studies Journal.

Are the times really a-changin'? It is undoubtedly true that focus on religion, especially Islam, has increased both among scholars and policy-makers. What is the explanation for this focus? Part of the explanation is likely to be the same story as with race: categories are 'naturalized'. Within the field of migration studies, ethnicity was coupled to culture, and cultures easily end up being described as static (see the critique raised in Baumann, 1999; and Jørgensen, 2009). Gullestad describes this tendency as culturalization, implying that culture becomes a language which is applied to interpret social differentiation and inequality, but thus risks contributing to the concealment of the underlying structural contradictions and hierarchies (2002: 57-58; cf. the discussion by Hier and Walby mentioned previously). She further claims that most people, including researchers, make use of both essentialist and constructivist notions of culture but in studies on migration the first type of explanations tend to be most common (ibid.). In a now much quoted article Stolcke makes a similar argument (1995). My aim here is not to point a finger, but to draw attention to how research contributes to specific understandings of social categories. Religion has somehow now entered this equation. People coming from countries with predominantly Muslim populations are understood first and foremost as Muslims. Bringing that identity into receiving non-Muslim societies with other values, (for example, being secular and 'modern' see Mørck, 1998) can create problems and lead to crises of national identity. This is probably not an uncommon phenomenon, but it is probably not a general fact either. My point here is that religion may now have become that concept in relation to which other social indicators or identity markers have an epiphenomenal status. Consequently, my argument is that this category should also be met with great sensitivity and reflexivity. Focusing too much on religion may take attention away from for instance the legal and economic situation of immigrants.

\section{Overemphasizing religion?}

The Diaspora mailing list, which is "a discussion and information channel for scholars interested in immigration and religion"10 had an interesting example of this logic. In March 2011 a Danish scholar posted a call for proposals for papers and discussants for a conference in Copenhagen under the title: 'Making European Muslims: Islam and the Struggle over Beliefs, Perceptions and

\footnotetext{
${ }^{10}$ http://www.diaspora.fi/mailing-list.html
} 
Identities among Children and Young People in Western Europe'. The call, which was not different from many other calls for papers on similar topics, nevertheless triggered strong reactions. One scholar wrote that "we" (researchers) should be far more reflective and be aware of "implicit extrastigmatization" by taking over dominant discourses of populist sentiments and bringing it into research. Other scholars argued that we should not avoid collecting data on Muslim communities, but be careful not to put the dominating discourse into our questions - resembling a form of neoorientalism. A consequence of this would also be a poorer knowledge production, as by focusing on some particular issues, we remain ignorant of many other important aspects of Muslim life. One scholar stated quite blatantly that: "I am so fed up with conferences on integrating Muslims in Western society, it is feeding an agenda that presupposes there is a problem".11 Were the respondents overreacting here, or are they actually making an argument that deserves attention? I would think the latter. When researching immigrants, both in relation to participation in different spheres of society (labour market, education, and politics) and everyday life, today the religious dimension is given more attention than previously. A possible consequence is that research produces knowledge, which indicates that immigrants are far more religious than they actually are, and immigrants are identified and positioned according to religion only (see Schmidt, discussed later in this article). The categorizers in this specific case come from the research communities themselves. This is perhaps more a hypothesis requiring further research than an empirical claim; we do of course find several studies also presenting a balanced view on religion. It should also be admitted that public attention on religion may not have the same character as the attention paid by research. Nevertheless, a focus on religion will inevitably lead to more research being conducted focusing on religion - thereby confirming that religion plays a larger role in the life of immigrants than in the life of natives. This issue will be discussed further in the next section.

\section{Methodological flaws - sampling on the dependent?}

When the literature on migrant transnationalism started to emerge in the late 1990s and early 2000s (see Levitt and Khagram, 2007 for an overview), and several studies showing evidence of transnational ties, identities and formations were published (some going as far as to claim that we are all transmigrants now (Castles, 2002), Portes published an interesting response to the development of the transnational literature in the journal Global Networks (Portes, 2001). He argued that many of the studies found transnational ties because they were explicitly looking for them. If a researcher goes, for instance, to an immigrant organization with social, political and economic ties to the homeland he/she is bound to find evidence of transnationalism, but to draw the conclusion that all migrants have the same types of ties and affiliations would be flawed. Portes warned against "sampling on the dependent", i.e. looking only for the data (transnational affiliations) which confirm the theory and disregard the data which does not. Such a biased sampling may led to flawed research results. Some researchers of religion have begun to acknowledge this as a potential risk. In an article published on Videnskab.dk, a site where research is disseminated more broadly beyond academia, Schmidt ${ }^{12}$ put forward exactly this reading of the literature. One thing is

\footnotetext{
${ }^{11}$ All these examples are taken from the debate (that is 'reply all' answers to the initial mail). The list does not contain any archive; hence the conversation is not saved anywhere.

${ }^{12}$ Garbi Schmidt is a Danish Professor with an academic background in science of religion.
} 
that the political and media discourse has stigmatized Muslims, but Schmidt claims that research in this field also carries some responsibility (Ebdrup, 2011). She says that due to an increased interest in religion, this dimension has been overemphasized in studies on immigrants. When researchers need to find Muslims, they often go to the Muslim organizations and Muslim spokespersons. Such organizations of course will address the religious issues, but on the other hand, we lose out on the non-religious aspects of immigrants' lives. Migrants may identify themselves as Muslims in a 'cultural' sense but in general understand religion as having a minor role in their life. The risk is that we limit ourselves to talking to the same persons again and again, and ignore the wider communities. Likewise, there has perhaps been much more focus on headscarves, rituals and mosques than on everyday life, than, as Schmidt says, on 'non-organized' Muslims' (ibid.).

This type of research has also triggered a reaction from the research subjects, the 'Muslims', some of whom have reacted to being labeled solely as religious beings, (as 'Muslims'). Akdogan, a socialdemocratic politician with a Turkish background wrote in a feature in the newspaper Information that: "When we arrived in the 1970s, we were guest-workers. Today we are just Muslims. It was far better to be a guest and worker than to be reduced to one's religious standpoint" (Akdogan, 2011). The sentence captures this dilemma well. We do need research producing knowledge on religious life and practices among Muslims and likewise for members of other religious traditions. At the same time however, we need to reflect on how we address these issues, as the debate on the Diaspora list also shows, and should be sensitive to the fact that we are dealing with a group being highly politicized. Studying Muslims under one heading, e.g. 'Muslims in the UK', might have consequences. Are those who are left out really all equally religious, and what does such a study tell us? Caldwell's essentialist description of Muslims in Europe (Caldwell, 2009) is illustrative of this type of study, but there numerous examples. The above discussion on over-emphasizing religion should be seen as a starting point for future studies as we still need more evidence to be able to draw stronger conclusions. Here I use the warnings offered by Portes as an analogy to a tendency I see emerging.

\section{In search of a conclusion}

Researching categories of difference is extremely complex and contains many pitfalls. As I have argued throughout this article, researchers are in a difficult situation when we want to study, analyze and disseminate knowledge about minorities and categories of difference in general. As the ethnographers have put it, we 'write differences' into being when we undertake our studies. Whether we work with the categories of race, ethnicity, gender, religion or class, we need to be reflexive about how we use these categories, and what the implications could be. I have tried to illustrate some of these consequences with examples from studies on race and Islam. If the subjects of research feel alienated and stigmatized by such studies, we cannot simply put our concepts into even more apostrophes and think that this will underline that we really do consider all categories to be socially constructed. This is especially pertinent if our writings sometimes also reify the categories and link them to social practices with real-life implications for the people we study. It is difficult to dispense with these categories, and it is not rare to experience unintentional uses. What would be the way forward or at least the way to deal with these ontological, theoretical, methodological, empirical and analytical challenges? I cannot provide definitive answers, I will, however, conclude by briefly bringing attention to a number of strategies derived from studies which I believe deal with at least some of these challenges and which also could be taken up in qualitative research studies. 
Comparative approaches - often some groups are stigmatized in specific ways locating the 'problem' in the group itself, for example as based in a particular culture, religion or ethnicity. In the Nordic countries, for instance, it is often repeated that Somalis do worse (in the labour market, inter alia) than other groups. However, studies like the one published by Benny Carlson on Somalis in Sweden and in Minneapolis in the US show, through a comparative approach, that if, indeed, the same group performs with marked differences in two different settings, then we should seek explanations in the structural frameworks rather than in the categories of religion or ethnicity (Carlson, 2006).

Normalizing - everyday life - instead of conducting research which explicitly forefronts the differences between groups, we could situate the differences within regular everyday life. The debate on Islam points toward this approach. Instead of approaching religious spokespersons, we could talk to people engaged in everyday life situations (rather than approaching them at the mosque) or even to non-practitioners. Recent studies by Jeldtoft and Nielsen, and Holm Pedersen and Rytter's edited volumes illustrate two such examples (Jeldtoft and Nielsen, 2011; Holm Pedersen and Rytter, 2011). Both volumes acknowledge the diversity of Muslims, have a nonessentialist stance, put emphasis on the many different aspects of life as a Muslim and have special focus on everyday life.

Giving the subjects a voice - let the people we study into the research (also Faber, this issue). Letting subjects have a larger role will at times disturb what we take for granted. An example is the 'At Home in Europe Project'. The project is funded and hosted by the Open Society Foundation and "focuses on monitoring and advocacy activities that examine the position of minorities in a changing Europe" (At Home in Europe Project, 2011). The strength of this project is that it engages with researchers, policymakers and communities, and explores issues involving the political, social, and economic participation of Muslims and other marginalized groups at the local, national, and European levels. The project is currently examining the level and nature of integration of Muslims in 11 cities across Europe. The Copenhagen case study showed that the group who identified as Muslims did not place as much importance on religion and what it means to be a Muslim as the media and sometimes research do (Open Society Foundations, 2011).

"It's not the economy stupid" - as the work of Yuval-Davis and other researchers (e.g. Crenshaw, 1991; McCall, 2005; Yuval-Davis, 2006a; 2006b) working on intersectionality has shown, different categories are not reducible to each other, and nor is there one underlying grand explanation for inequality. So, for example, the Marxist understanding that everything can be reduced to the economic system may not be the most productive for analyzing categories of differences. Rather, we should try to integrate the intersectional perspective when working with categories of difference. This, indeed, is something (some) statisticians have been doing for a longer time, but qualitative studies have been working in a far more segregated manner on single categories. Hier and Walby (2006) and Gullestad (2002) mentioned previously likewise connect to this approach.

Transnational perspectives - we should be careful not to fall into the trap of explaining categories with strict reference to the nation-state, such as processes of integration, and thereby reproduce methodological nationalism. Focusing on processes which transgress and transform contemporary societies, for example, transnationalizing civil societies as Faist has phrased it (Faist, 2000), will also 
make it possible to show how categories are dynamic and flexible. On a micro-level there is neither anything won by describing immigrants as torn between homeland nostalgia and complete assimilation but it is exactly the negotiations and the in-between and hybrid identifications which offer an analytical terrain.

Expanding the scope of the research - instead of singling out a specific minority group or social division, we can think more broadly and design studies which investigate the relations and interactions between different groups (minority and majority) in specific settings. For example, not investigating Muslims in a single city, but all religious denominations and traditions in that particular city; focusing on diversity and not on the difference of a single group. Martikainen's study on immigration and religious diversity in the city of Turku, Finland is an example of this approach (Martikainen, 2009).

Thinking beyond racism in race theory - Pitcher's work on race theory shows that race theory has been structured by an ontology inevitably motivating critiques of racism and thereby installing a dichotomy between racism and non-racism which might be too reductive to capture the complexities of the category of race. Race has wider meanings than racism, e.g. in relation to consumption. Anti-racism is extremely important, and if it looks like racism it probably is racism, but avoiding the category of race does not make it disappear and race continues to signify and to be a part of our social repertoire of meaning-making, therefore we should reflect on how to use race not solely in relation to racism..$^{13}$

In sum, the solution is not to get rid of categories of difference. They can be necessary for the outlined purposes. The study and application of the various categories of difference have individual and particular histories however, as illustrated with the examples of race and religion, and these histories must be understood in the broader contexts of colonialism, racism, new forms of discrimination and globalization. The latter has especially led to a 'diversification of diversity' as Vertovec puts it (Vertovec, 2007) and the implications of categorizing will keep on posing a challenge. Urry and Law have argued that the power of social inquiry, of its epistemologies and methods resides in the ways it helps to produce social realities (Urry and Law, 2004). The examples I have given in the conclusion all point to approaches acknowledging that we work with and study categories of difference but at the same articulate analytical sensitivity and reflexivity.

\section{References}

Aidt, M. and Hervik, P. (2009). Sprogbrug. Cultures, Nr. 1 august-september 2009: 21-23.

Akdogan, Y. (2011). Fra gæstearbejder til muslim. Information, 22. August 2011.

Ali, S. (2006). Racializing research: Managing power and politics? Ethnic and Racial Studies, 29 (3), 471-486.

American Anthropological Association (1977). Responses to OMB Directive 15.

\footnotetext{
${ }^{13}$ The approach was outlined at a keynote lecture at the ECREA seminar on Media, Migration and Diaspora in Maynooth, 2-3. December 2011. See more on http://sites.google.com/site/pitcherben/
} 
American Anthropological Association (1998). Statement on 'Race' (May 17, 1998).

American Sociological Association (2003). Statement of the ASA on the Importance of Collecting Data and Doing Social Scientific Research on Race. Washington: ASA.

Anderson, B. (1991). Imagined Communities. $2^{\text {nd }}$ edn. London: Verso.

Baumann, G. (1999). The Multicultural Riddle: Rethinking National, Ethnic, and Religious Identities. London: Routledge.

BBC (2011). New UK 12 August: England riots: “The whites have become black" says David Starkey. Available at: http://www.bbc.co.uk/news/uk-14513517

Berger, P., L. and Luckmann, T. (1966). The Social Construction of Reality: A Treatise in the Sociology of Knowledge. Garden City, NY: Anchor Books.

Best, J. (2004). More Damned Lies and Statistics. University of California Press.

Borges, J. L. (1999[1942]). John Wilkins' Analytical Language. Selected nonfictions: Jorge Luis Borges. Penguin Books.

Bourdieu, P. (1990). In Other words - Essays Toward a Reflexive Sociology. Stanford: Stanford University Press.

Caldwell, C. (2009). Reflections on the revolution in Europe: immigration, Islam, and the West. New York: Doubleday.

Callister, P., Didham, R. and Kivi, A. (2009). Who are we? The conceptualisation and expression of ethnicity. Official Statistics Research Series, 4.

Carlson, B. (2006). Somalier i Minneapolis - en dynamisk affär. Malmö: Zufi.

Castles, Stephen (2002). Migration and Community Formation under Conditions of Globalization. International Migration Review, Vol. 36 (4), 1143-1168.

Crenshaw, K. (1991). Mapping the Margins: Intersectionality, Identity Politics, and Violence against Women of Color. Stanford Law Review, Vol. 43 (6), 1241-1299.

Davies, B. and Harré, R. (1990). Positioning: The Discursive Production of Selves. Journal for the Theory of Social Behaviour, Vol. 20 (1), 43-63.

DR (2009). DF bag ny statistik om indvandrere. Available at: http://www.dr.dk/P1/orientering/indslag/2009/12/17/161424.htm 
Ebdrup, N. (2011). Forskere bilder os ind, at indvandrere er religiøse. Videnskab dk. Available at: http://videnskab.dk/kultur-samfund/forskere-bilder-os-ind-indvandrere-er-religiose

Eide, E. (2010). Strategic essentialism and Ethnification. Hand in a Glove? Nordicom Review, Vol. 31(2): 63-78.

Faist, T. (2000). The volume and dynamics of international migration and transnational social spaces. Oxford University Press.

Ferrante, J. and Brown, P. (Eds.) (1998). The social construction of race and ethnicity in the United States. New York: Addison-Wesley.

Foucault, M. (2002[1969 original in French]). The Archaeology of Knowledge. Oxford: Routledge.

Fraser, N. (2003). Social Justice in the Age of Identity Politics: Redistribution, recognition and Participation. In N. Fraser and A. Honneth (eds.) Redistribution or Recognition: A Politicalphilosophical Exchange. London: Verso: 7-109.

Gilroy, P. (1992). The Black Atlantic: Modernity and Double Consciousness. Cambridge: Harvard UP.

Gilroy, P. (2000). Against Race: Imagining Political Culture Beyond the Color Line. Cambridge, Massachusetts: The Belknap Press of Harvard University Press.

Guardian (2011). Available at: http://www.guardian.co.uk/uk/series/reading-the-riots

Gullestad, M. (2002). Det norske sett med andre øyne. Oslo: Universitetsforlaget.

Hier S. E. and Walby, K. (2006). Competing Analytical Paradigms in the Sociological Study of Racism in Canada. Canadian Ethnic Studies, Vol. 38(1), 83-104.

Holm Pedersen M, and Rytter, M. (eds.). Islam og muslimer i Danmark - Religion, identitet og sikkerhed efter 11. september 2001. København: Museum Tusculanums Forlag.

Jeldtoft, N. and Nielsen, J. S. (eds.) (2011). Methods and Contexts in the Study of Muslim Minorities: Visible and Invisible Muslims. Philadelphia: Taylor \& Francis Inc.

Jenkins, R. (1996). Ethnicity etcetera: Social anthropological points of view. Ethnic \& Racial Studies, Vol. 19 (4), 807-822.

Jørgensen, M. B. (2009). National and Transnational Identities: Turkish Organising Processes and Identity construction in Denmark, Sweden and Germany. PhD Dissertation. AMID/SPIRIT: Aalborg University.

Jørgensen, M. B. (Forthcoming). Denmark: Policy-Research-dialogues dominated by politics. In R. Penninx and P. Scholten (eds.) Research-policy dialogues on migration and integration in Europe: towards a conceptual framework. Amsterdam: Amsterdam University Press. 
Keskinnen, Suvi; Tuori, Salla; Irni, Sari and Mulinari; Diana (eds.) (2009). Complying with Colonialism. Gender, Race and Ethnicity in the Nordic Region. Farnham: Ashgate.

Laswell, D. H. (1936). Politics: Who Gets What, When, How. New York: McGraw-Hill.

Lentin, A. (2008). Europe and the Silence about Race. European Journal of Social Theory, 11, 487-503.

Levitt, P. and Khagram, S. (2007). The Transnational Studies Reader. Intersections and Innovations. Oxford: Routledge.

Lieberman, L. (1968). A Debate over race: A Study in the Sociology of Knowledge. Phylon, 29, 127141.

Martikainen, T. (2009). Religious diversity beyond the cosmopolis: Immigration and the religious field in the City of Turku, Finland. Religion, 39 (2), 176-181.

McCall, Leslie (2005). The Complexity of Intersectionality. Journal of Women in Culture and Society, Vol. 30 (3), 1771-1800.

Morris, L. (2002). Managing Migration - Civic stratification and migrants' rights. London \& New York: Routledge.

Murji, K. and Neal, S. (2011). Riot: Race and Politics in the 2011 Disorders. Sociological Research Online, 16 (4).

Mørck, Y. (1998). Bindestregsdanskere: Fortællinger om køn, generationer og etnicitet. Forlaget Sociologi.

Nayak, A. (2006). After race: Ethnography, race and post-race theory. Ethnic and Racial Studies, 29 (3), 411-430.

Nayak, A. (2007). Critical Whiteness Studies. Sociology Compass, 1 (2), 737-755.

OMB (1997). Revisions to the Standards for the Classification of Federal data on Race and Ethnicity. Washington: US Government.

Open Society Foundations (2011). Muslims in Copenhagen. New York: Open Society Foundations.

Portes, A. (2001). Introduction: the debates and significance of immigrant transnationalism. Global Networks, 1 (3), 181-193.

PROMINSTAT (2010). Statistics on Migration, Integration and Discrimination in Europe. PROMINSTAT Final Report. European Commission.

Rallu, J., Piché, V. and Simon, P. (2006). Demography and ethnicity: An ambiguous relationship. In G. Caselli, J. Vallin and G. Wunsch (eds.), Demography: Analysis and Synthesis. A treatise in population studies. Amsterdam: Elsevier, 531-549. 
Regulation (EC) No 862/2007 of the European Parliament and the Council of 11 July 2007 on Community statistics.

Rosenblum, K. and Travis, T-M. C. (2008). The Meaning of Difference: American Constructions of Race, Sex and Gender, Social Class, Sexual Orientation, and Disability. McGraw-Hill Companies.

Said, E. (1978). Orientalism. Vintage Books.

Said, E. (1993). Culture and Imperialism. Vintage Books.

Squires, J. (2007). The New Politics of Gender Equality. Basingstoke: Palgrave Macmillan.

Simon, P (2011). Lighter than blood: ethnic statistics and equality politics in racialized European societies. Presentation given at the IMISCOE Eighth Annual Conference: Dynamics of European Migration Space: Economy, Politics and Development, Warsaw, Poland, 7-9 September 2011.

St Louis, B. (2005). The difference that sameness makes. Ethnicities, 5 (3), 343-364.

Stolcke, V. (1995). Talking Culture. New Boundaries, New Rhetorics of Exclusion in Europe. Current Anthropology, Vol. 36(1), 1-24.

US Census Bureau (1977). Statistical Directive No. 15 "Race and Ethnic Standards for Federal Statistics and Administrative Reporting".

Vertovec, S. (2007). Super-diversity and its implications. Ethnic and Racial Studies, 30 (6), 1024-1054.

Walby, S. (2007). Complexity Theory, Systems Theory, and Multiple Intersecting Social Inequalities. Philosphy of the Social Sciences, 37 (4), 449-470.

Wimmer, A. and Glick Schiller, N. (2002). Methodological nationalism and beyond. Nation state building, migration and the social sciences. Global Networks, 2 (4), 301-334.

Yuval-Davis, N. (2006a). Belonging and the politics of belonging. Patterns of Prejudice, 40 (3), 198214.

Yuval-Davis, N. (2006b). Intersectionality and Feminist Politics. European Journal of Women's Studies, 13 (3), 193-209.

\section{Author}

Martin Bak Jørgensen is an Assistant Professor at the Department of Culture and Global Studies at the University of Aalborg, Denmark. Email: martinjo@cgs.aau.dk 